\title{
PREPARANDO AL VERDADERO CIUDADANO Y CENTINELA EJEMPLAR QUE VELARÁ POR EL HONOR DE LA República. El SaLVAdOR, 1933
}

\author{
Gerardo Monterrosa-Cubías
}

E n diciembre de 1931 inició en El Salvador un período político que los historiadores han denominado "el martinato". Se trató del ascenso al poder a través de un golpe de Estado del general Maximiliano Hernández Martínez. Intelectual antiimperialista durante los años veinte, profesor de la Escuela Militar y seguidor de la teosofía, Martínez enfrentó al comienzo de su mandato las insurrecciones acaecidas en el occidente del país en enero de 1932. Ante la negativa de Washington de reconocer a un Gobierno instaurado por medio de una asonada, los levantamientos cayeron como anillo al dedo para el general. La represión indiscriminada se convirtió en castigo ejemplarizante, los sectores conservadores le endosaron su respaldo y la propaganda anticomunista erigió a Hernández Martínez como "el salvador de la patria”. Las autoridades estadounidenses, aunque no reconocieron el régimen salvadoreño sino hasta 1934, tenían en Martínez a un ferviente aliado anticomunista.

Y, precisamente, en estos años de consolidación del régimen —el general Martínez dejó la Primera Magistratura en mayo de 1944- se ubica el documento que ahora nos ocupa, titulado "El Instituto Nacional y su Régimen Disciplinario", publicado en el número de la revista del Instituto Nacional General Francisco Menéndez (INFRAMEN) correspondiente al segundo semestre de 1933 — año III, núm. 20, julio a diciembre de 1933-. Un ejemplar de este número se resguarda en Colecciones Especiales de la Biblioteca Florentino Idoate, de la Universidad Centroamericana José Simeón Cañas (UCA), de San Salvador — con signatura L45 R434p (1932-1942) - El aspecto peculiar de este número reside en la justificación sobre la militarización de esta casa de estudios esbozada por las autoridades. Ante las voces disidentes, los responsables de concretar dicha medida aprovecharon las páginas de la revista para explicar los objetivos que perseguían. Fue así como el doctor Salvador Pérez Gómez, docente del Instituto Nacional, afirmó que la militarización respondía a "un régimen de orden y exactitud; no es una disciplina militar; es una disciplina escolar mantenida por militares; y militares de escuela que hacen del cumplimiento de su deber de educadores sagrado ministerio" (Pérez, 1933: 2-3). Además, esta

Gerardo Monterrosa Cubías, estudiante del Doctorado en Ciencias Sociales y Humanísticas, en el Centro de Estudios Superiores de México y Centroamérica de la Universidad de Ciencias y Artes de Chiapas, México. Correo electrónico: gerardomonterrosa20@gmail.com.

Recibido: 15 de octubre de 2015. 
medida se encontraba, según sus apologetas, en plena concordancia con la Constitución política de 1886, en la que se establecía el servicio militar obligatorio. Por consiguiente, si todos los salvadoreños hábiles de dieciocho a cincuenta años eran soldados, su instrucción debía correr por cuenta del Estado, y nada mejor que la temprana juventud para infundir el orden, la disciplina y la gallardía que permiten delinear "hombres dignos que prefieran la muerte al pie del Pabellón, antes que dar un paso atrás, o el beso del Iscariote, o la rendición cobarde, infame y traicionera" (Severo, 1933: 57-60).

No obstante, más allá de la parafernalia oficialista y los numerosos retratos de las paradas militares de los alumnos y las visitas que el general Martínez realizaba cuando en el INFRAMEN inauguraba el año lectivo, es preciso lanzar la siguiente pregunta: ¿desde qué parámetros teóricos podemos interpretar la militarización de este centro de estudios? Una respuesta exhaustiva escapa al espacio asignado para comentar este texto; sin embargo, en aras de una lectura reflexiva sobre el militarismo que campeó en Centroamérica durante el siglo XX, es preciso indicar posibles derroteros.

Pues bien, el martinato constituye para la historia salvadoreña el ascenso del militarismo, fenómeno que no representó únicamente la entronización de la institución castrense en el Ejecutivo, sino también - como muestra el documento- la promoción de ciertos valores acordes con el proyecto gubernamental. Leonardo Morlino, teórico de las ciencias políticas, denominó a esta estrategia proceso de socialización. De acuerdo con ello, el principal objetivo consistía en educar a las nuevas generaciones según los principios que el régimen ponderaba como fundantes. Debido a este factor la escuela se convertía "en tierra de conquista para los nuevos gobernantes" (Morlino, 2005: 122), un terreno fértil donde el régimen se disponía a obtener legitimidad. Por ello, a partir de 1932, año en que la Dirección y Subdirección del INFRAMEN pasaron a manos castrenses, el orden, la disciplina y la instrucción militar se establecieron como baluartes del status quo. Desde esta fecha "el coche fúnebre del progreso dentro del orden”, en palabras de García Márquez, rigió la tabla axiológica que forjaría a los ciudadanos del martinato.
Al respecto, si la militarización del INFRAMEN respondióa un proyectogubernamentaly el arriboalpoder del general Martínez inauguró la etapa del militarismo, es posible interpretar también este fragmento desde lo estipulado por Michel Foucault, quien en su célebre obra Vigilar y castigar: nacimiento de la prisión, aludió al sueño militar de la sociedad. Para este filósofo e historiador de las ideas, "[...] su referencia fundamental se hallaba no en el estado de naturaleza, sino en los engranajes cuidadosamente subordinados de una máquina, no en el contrato primitivo, sino en las coerciones permanentes, no en los derechos fundamentales, sino en la educación y formación indefinidamente progresivas, no en la voluntad general, sino en la docilidad automática" (Foucault, 1978: 197). Este parámetro de interpretación conduce a preguntarnos sobre el sueño militar de la sociedad forjado durante el martinato, sobre todo en un período en el que la lucha contra el enemigo interno - encarnado por el comunismo - había desplazado las guerras intestinas entre Gobiernos centroamericanos. En este sentido, el hecho de considerar a todos los salvadoreños desde los dieciocho hasta los cincuenta años como soldados y procurar su instrucción militar — con los valores que este tipo de formación conllevaba- nos aproxima al sueño militar de la sociedad de estos años, el cual, paradójicamente, es añorado por buena parte de la población que hace del general Martínez el militar más recordado y siempre citado cuando el orden y la disciplina resultan ponderados.

\section{Referencias bibliográficas}

Foucault, Michel (1978). Vigilar y castigar: nacimiento de la prisión. México: Siglo XXI.

Morlino, Leonardo (2005). Democracia y democratizaciones. México: Centro de Estudios de Política Comparada. Pérez Gómez, Salvador (1933), "El Instituto Nacional y su régimen disciplinario". En Revista del Instituto Nacional Francisco Menéndez, núm. 20, julio-diciembre de 1933.

Severo López, Vidal (1933). "La parada militar del Instituto Nacional". En Revista del Instituto Nacional Francisco Menéndez, núm. 19, enero-junio de 1933. 


\section{El Instituto Nacional y su Régimen Disciplinario}

\author{
Por el Dr. Salvador Pérez Gómez
}

Existe un prejuicio que, nacido de la incomprensión o de la malicia, tiene honda raigambre en el ánimo de las masas: es el de creer que en el Instituto Nacional se observa una disciplina netamente militar. Nada más alejado de la verdad; el régimen disciplinario actual del Segundo Centro Docente de la República, es no más que un régimen de orden y exactitud; no es una disciplina militar; es una disciplina escolar mantenida por militares; y militares de escuela que hacen del cumplimiento de su deber de educadores sagrado ministerio. La disciplina militar es severa en grado superlativo: el arresto, la bartolina, el código, la ordenanza etc., campean en toda su plenitud, mientras que los correctivos que se aplican a los alumnos que se hacen acreedores a ellos son los correctivos que aplicaría el pedagogo más escrupuloso, es decir, son los aconsejados por los cánones de la Pedagogía moderna. Quienes en loco afán de notoriedad barata, picando de saberlo todo, critican "porque sí" el régimen implantado, es porque, seguramente nunca se han acercado al Instituto y hablan a través de las palabras de algún alumno que por mala conducta o notoria desaplicación e incompetencia, haya sido eliminado por la Dirección del plantel.

La disciplina debe ser racional y nunca coercitiva; debe nacer espontánea del fondo del individuo para que en el curso de la vida, se conduzca noblemente sin necesidad de supervigilancias, íntimamente convencido de la suprema satisfacción que proporciona la rectitud de los procederes.

Hermosos postulados de la Pedagogía moderna: tal debe ser el ideal del educador: conseguir que el educando practique el bien por el bien mismo. Mas, para llegar a tan hermoso realismo es menester crear en el educando el HÁBITO DEL BIEN. Quienes hayan siquiera abierto un libro de Psicología Pedagógica y Ética (Ciencias mancomunadas de la Educación) recordarán el valor educativo que la palabra HÁBITO representa: si, para el cuerpo, existen los movimientos reflejos (movimientos medulares) también para la vida del espíritu existen una serie de actos que el sujeto ejecutará espontánea y constantemente provenidos de las profundidades de su Complejo Psíquico. Ahora bien, estos actos que podríamos llamar reflejos del espíritu o Alma como la llama la Ciencia Teosófica. ¿De qué naturaleza serán? ¿Buenos o malos? ¿Serán inspirados por Ormuz o por Arimán? He allí la obra del educador: crear hábitos de orden, puntualidad, estudio, mutuo respeto, tolerancia, dignidad, etc., pues creando en el joven educando esos HÁBITOS, esa segunda naturaleza espiritual, todo estará conseguido y el blanco Dios del Bien habrá triunfado sobre el negro espíritu del mal.

Para infundir en los alumnos tales hábitos y cumplir plenamente esa labor de suyo difícil, la Dirección ha tenido que enfrentarse no pocas veces con la incomprensión de algunos, que no quieren entender que el saber es áspero Calvario para el cual muchos son los llamados y pocos los escogidos.

Una de las características dominantes en el actual gobierno del Instituto Nacional es la absoluta imparcialidad en las calificaciones mensuales y de fin de año de los alumnos. El sistema de exámenes escritos en los cuales no figura ni el nombre del alumno ni el del colegio de donde proviene es garantía de absoluta imparcialidad, pues de esta manera el examinador analiza no más que el trabajo escrito, alejado de toda influencia extraña a su misión de examinador.

Hay más: ese espíritu de puntualidad infundido en el alumnado se ha reflejado también en el cuerpo de Profesores, quienes no sólo concurren a impartir sus clases con toda exactitud sino que, voluntariamente han tomado más horas de trabajo de las que realmente les corresponden.

Para desarrollar en el profesorado el espíritu de solidaridad y fraternidad se han constituido (el profesorado y personal Administrativo) en Sociedad de Ahorros y Beneficencia cuyas proyecciones en el futuro son de incalculable valor.

Naturalmente, para poder apreciar y manifestar “Urbe et Orbi" esta labor tan eficaz como compleja es menester, estar cerca del Instituto y hablar con conocimiento pleno de causa.

El prestigio de que ahora goza el Instituto es tal que hasta asociaciones literarias como 
el Ateneo de El Salvador por ejemplo, le buscan para desarrollar en su seno hermosos torneos de inteligencia como el Campeonato de Oratoria recientemente celebrado ante numerosa $y$ distinguida concurrencia de académicos, ateneístas y otras personas, torneo en el cual un alumno del Quinto Año del mismo Instituto se llevó triunfalmente las Palmas de Oro.
Mucho tendríamos que añadir pero lo dicho basta para demostrar CON HECHOS el esfuerzo que el Sr. Director Coronel e Ingeniero Carlos Mejía Osorio y el Señor Subdirector Mayor y Br. Rafael Arévalo Merino hacen para que este Instituto sea timbre de honor y orgullo para el actual Gobierno que, acertadamente, les confiara tan delicados y honrosos cargos.

\section{SALUS POPULI SUPREMA LEX}

Fuente: Pérez Gómez, Salvador (1933). "El Instituto Nacional y su régimen disciplinario". En Revista del Instituto Nacional Francisco Menéndez, núm. 20, julio-diciembre, pp. 2-3.

Foto 1. Sumario del número de la Revista del Instituto Nacional General Francisco Menéndez, correspondiente al año III, núm. 20, julio a diciembre de 1933

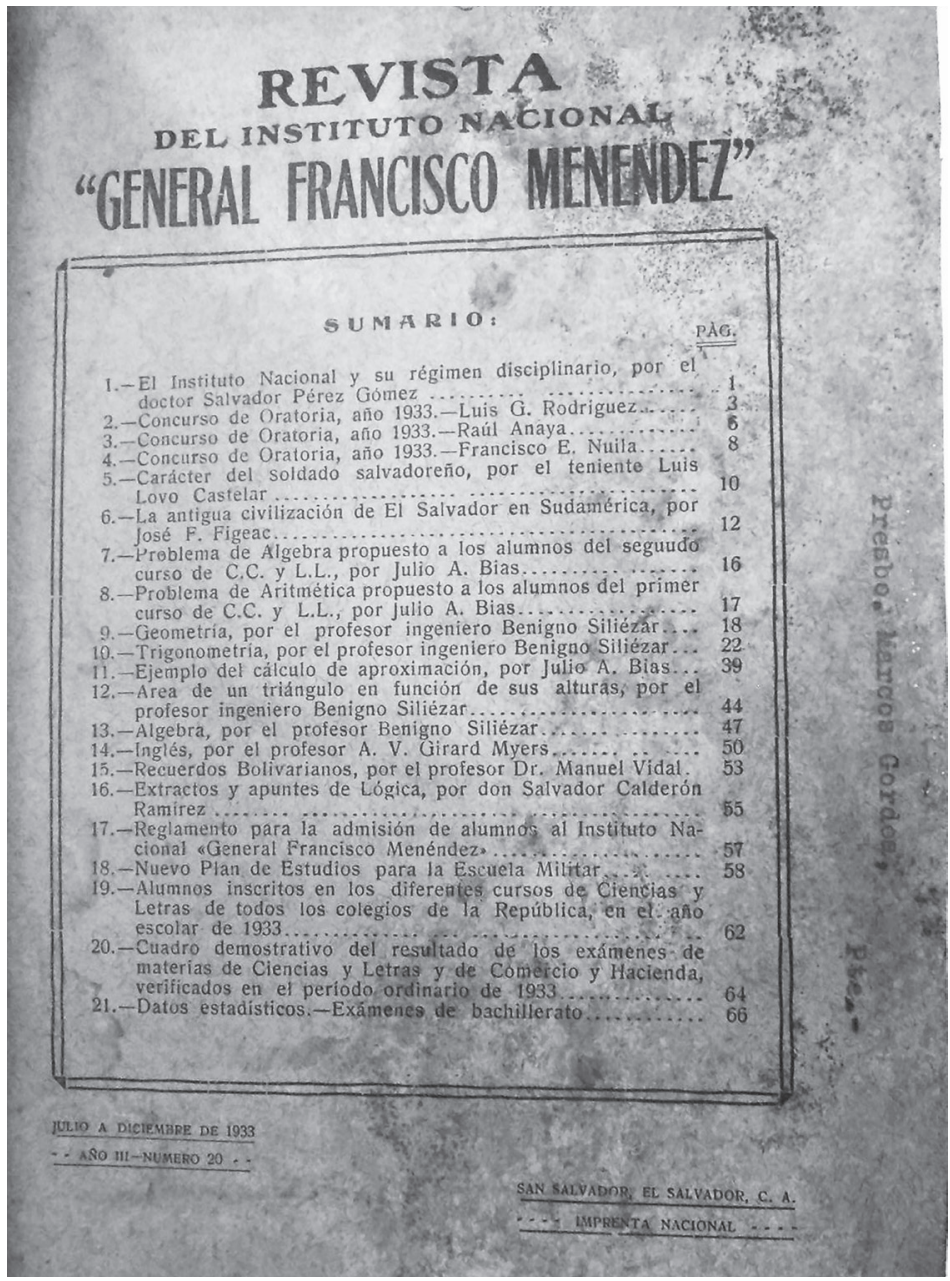

Fuente: Colecciones Especiales de la Biblioteca Florentino Idoate, Universidad Centroamericana José Simeón Cañas, San Salvador. 


\section{Fotos 2 y 3. Documento “El Instituto Nacional y su Régimen Disciplinario”, de Salvador Pérez Gómez}
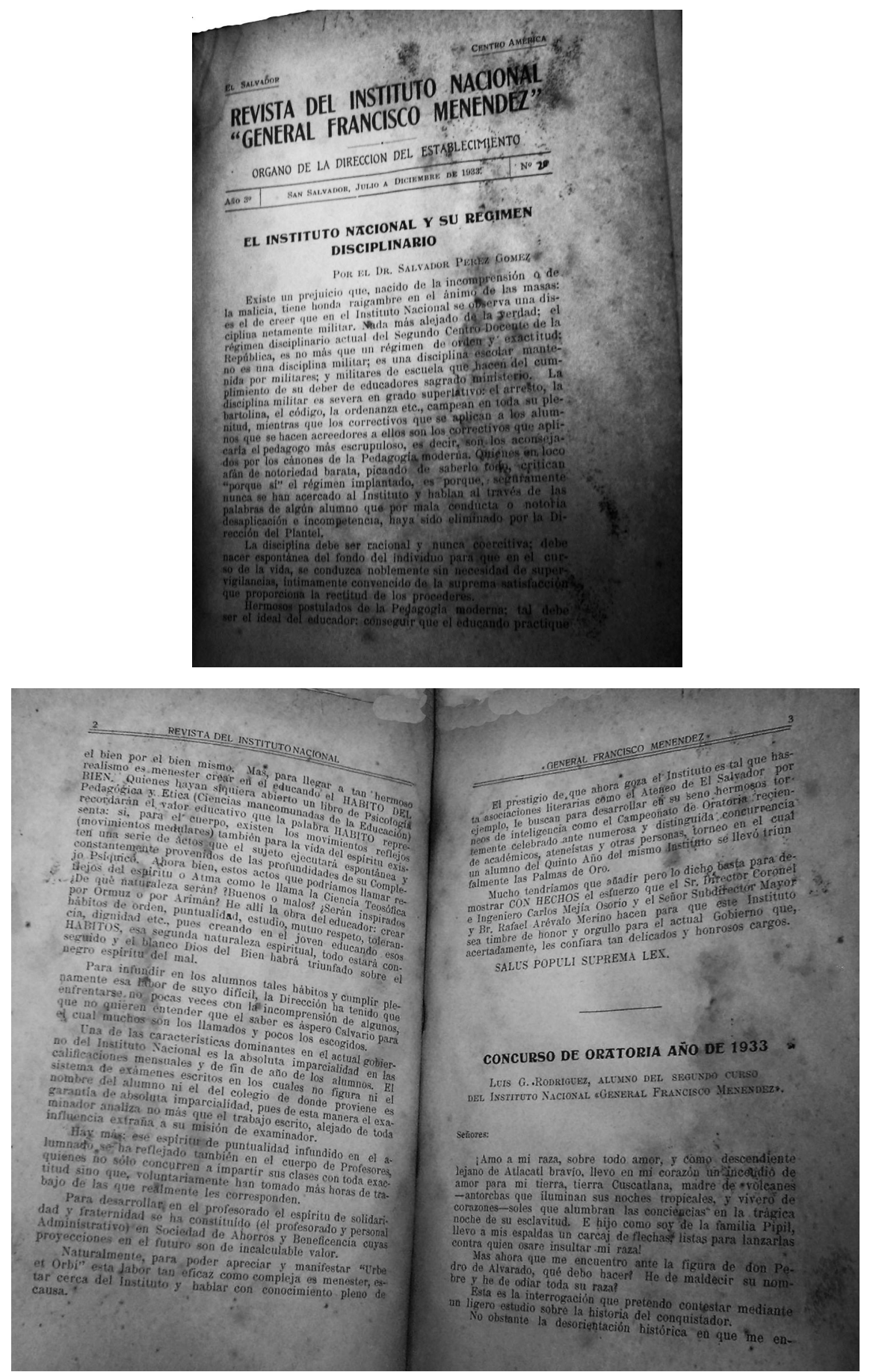

Fuente: Revista del Instituto Nacional General Francisco Menéndez, año III, núm. 20, julio a diciembre de 1933. En Colecciones Especiales de la Biblioteca Florentino Idoate, Universidad Centroamericana José Simeón Cañas, San Salvador. 


\section{Foto 4. Presidente de la República, general Maximiliano Hernández Martínez (1931-1944), junto con autoridades del Instituto Nacional General Francisco Menéndez, en 1932}

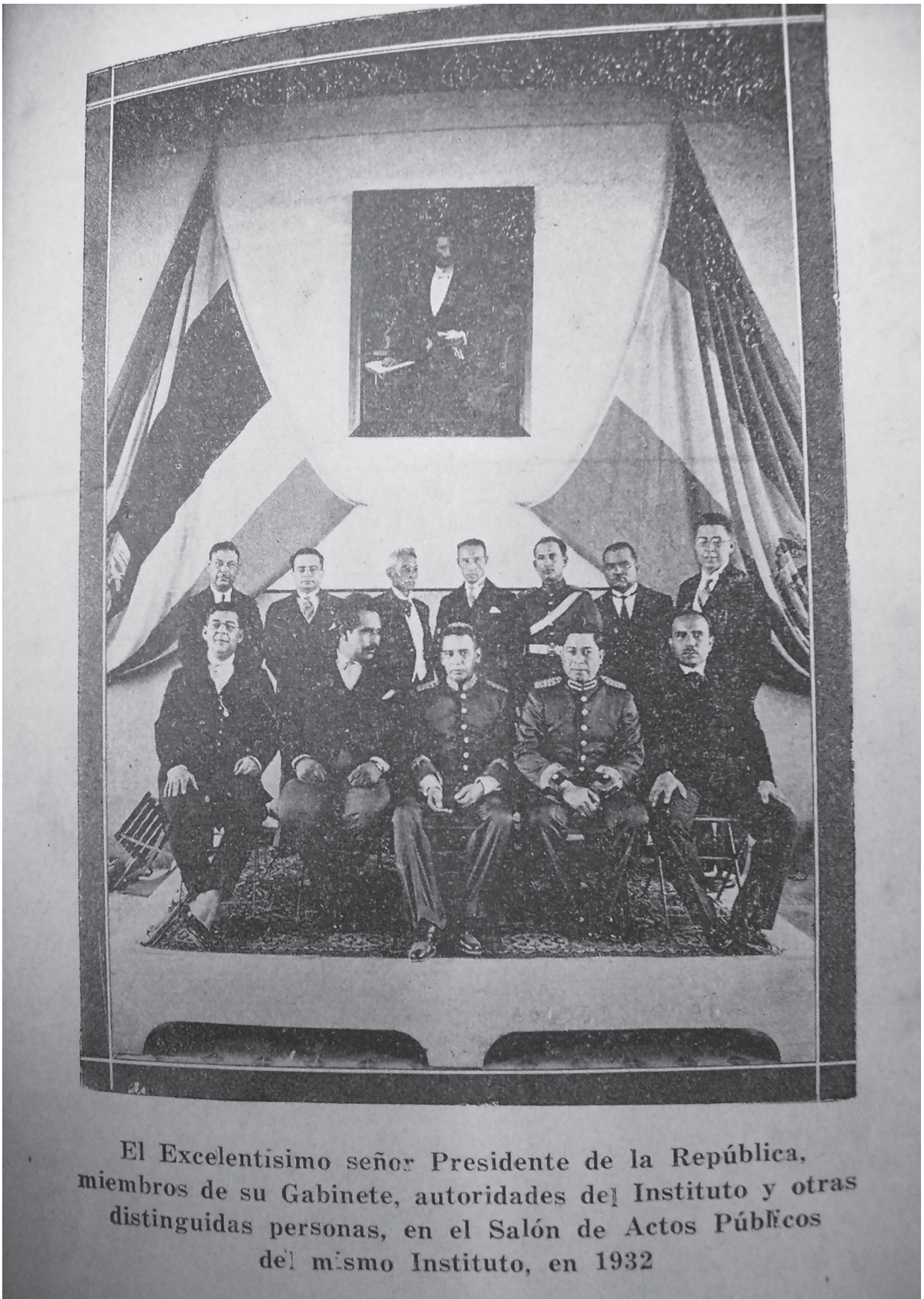

Fuente: Revista del Instituto Nacional General Francisco Menéndez, año III, núm. 20, julio a diciembre de 1933. En Colecciones Especiales de la Biblioteca Florentino Idoate, Universidad Centroamericana José Simeón Cañas, San Salvador. 